such as soil type, commodity farmed, job, process (manual vs mechanical), quartz\% and weather variables (eg, wind and humidity during the week prior to or during sampling) were entered into regression models to identify determinants of respirable quartz exposure.

Results Over-exposure to respirable quartz was found on all three farms and for most jobs. The highest concentration was $626 \mu \mathrm{g} \cdot \mathrm{m}-3$ and $12 \%, 13 \%$ and $0 \%$ of measurements were $>100 \mu \mathrm{g} \cdot \mathrm{m}-3$ (a common OEL) for the sandy, sandy loam and clay soil farms respectively. Nine per cent were $>50 \mu \mathrm{g} . \mathrm{m}-3$ on the clay farm. Commodity, job, process, humidity on the day of measurement and respirable dust concentration were significantly related to quartz exposure, but not soil type. In separate models, wind and humidity variables in the past week were also significantly related to quartz exposure, but not soil type.

Conclusions There is potential for overexposure in some farm settings. Surprisingly, soil type was not a determinant of respirable quartz concentrations; the nature of farming and weather variables may be more informative of exposure risk than soil type.

\title{
Farming 2
}

\section{SILICA EXPOSURE AND DETERIMINANTS OF EXPOSURE IN FARMING}

Andrew Swanepoel, 1 David Rees, ${ }^{2}$ Hans Kromhout, ${ }^{3}$ Cornelia Swanepoel ${ }^{4}{ }^{1}$ University of the Witwatersrand, Johannesburg, South Africa; ${ }^{2}$ National Institute for Occupational Health, Johannesburg, South Africa; ${ }^{3}$ Utrecht University, Utrecht, The Netherlands; ${ }^{4}$ North-West Uiversity, Potchefstroom, South Africa

10.1136/oemed-2011-100382.161

Objectives Silica causes multiple serious diseases yet little is know about silica exposure in farming. Hence the objectives to quantify personal respirable quartz exposure on three farms (with sandy, sandy loam or clay soil) and to identify determinants of exposure.

Methods 298 personal respirable dust and quartz measurements were done on the farms. Values below the limit of detection were estimated using multiple imputation. Variables 